\title{
Study on Appropriateness of Improved Soft Rock Residual Soil for Heavy Haul Railway Subgrade
}

\author{
Jiangjiang Zhu, a, Qiang Luo ${ }^{1, \text { b }}$, and Xueqi Zhan ${ }^{2, c}$ \\ ${ }^{1}$ School of Southwest Jiaotong University, Chengdu 610031, China \\ ${ }^{2}$ China Railway Si yuan Survey and Design Group Co. Ltd., Wuhan 430063, China \\ ajjblue28@163.com, ${ }^{b}$ lqrock@swjtu.edu.cn, ${ }^{\circ} 541142466 @ q q . c o m$
}

Keywords: completely weathered soft rock; cement-soil; heavy haul railway; engineering property; compaction technology

\begin{abstract}
In order to explore the appropriateness of soft rock residual soil used as filler of heavy haul railway embankment below subgrade bed, relying on the newly built Menghua heavy haul railway project, taking the filler from Yueyang to Jian as the research object, the basic engineering properties and improvement measures are studied through the laboratory geotechnical test; the field filling test is developed, and the key control parameters and compaction technology are discussed. The test shows that the soft rock residual soil is a high liquid limit silty clay, which belongs to the D group filler, and should be reinforced or improved when used for embankment filler, and the optimum mixing ratio of cement improved soil is $3.5 \%$; when slackly lay thickness is $40 \mathrm{~cm}$, water content is controlled in the range of $w_{\mathrm{opt}}<w<w_{\mathrm{opt}}+2 \%$, and the filling quality of embankment is well by using the rolling compaction combination of two times static pressure + weak vibration one time and static pressure one time + strong vibration one time and static pressure one time. Therefore, the improved soft rock residual soil can be used to filling the heavy haul railway embankment below subgrade bed.
\end{abstract}

\section{Introduction}

The Menghua heavy haul railway is the largest special transportation line for coal under construction in China, which starts from Inner Mongolia Holle Jilin to Ji'an in Jiangxi province. The formation along the Yueyang to Ji'an is mainly weathered or easily weathered soft rock, such as the Proterozoic slate, schist, phyllite and mudstone, siltstone, are mostly interbedded and unevenly weathered. Among them, the completely weathered soft rock filler accounts for about $70 \%$ of the total excavation volume of $3284 \times 10^{4} \mathrm{~m}^{3}$, if it can be used to filling embankment, it will solve the problem of massive spoil and borrow, reduce the damage of the local ecological environment and produce huge economic benefits. Therefore, it is of great practical significance to study the appropriateness of completely weathered soft rock used as filler of heavy haul railway embankment below subgrade bed. 
With the traffic engineering massive construction at home and abroad, such as railway and highway, the development of subgrade engineering is greatly promoted, and the research of subgrade filler is also more comprehensive and deeper by scholars in various countries. The feasibility of the soft rock filling subgrade is studied by BO Gonglin and KOJIMA Kobayashi ${ }^{[1]}$, they considered that the unbroken block soft rock is easily powdered after the water immersed, as subgrade filler, it should be fully crushed and rolled with a large-scale compaction machine. Based on the analysis of the basic mineral composition and the properties of enduring collapse of the weathered soft rock filler, and combining the mechanical strength of the rock and the compaction test results, Mingxin Zheng ${ }^{\text {[2] }}$ thinks that the weathered soft rock can be used in the filling of the high speed railway subgrade, and a preliminary determination method is put forward. Wei Yuan ${ }^{[3]}$ carried out laboratory and model tests on the soft rock distributed along the Wuhan-Guangzhou passenger dedicated line, he concluded that the soft rock filler has sufficient shear strength and stiffness, but the water stability is poor when it is used to fill the embankment below the subgrade bed of high speed railway. Mark ${ }^{[4]}$ took the weathered soft phyllite filler as the research object, the mineral composition, physical chemistry properties and strength properties of the soft rock was tested, and the chemical improvement was carried out, by contrast, the mechanical properties of the chemical improved soil had been greatly enhanced. With the combination of model test and numerical analysis, Qixiang Qing ${ }^{[5]}$ discussed the deformation mechanism of embankment filled with soft rock under cyclic loading, and considered that the quality of embankment met the code requirements, the soft rock filler can be used in railway subgrade.

Above all, most of the existing research objects are mainly high-speed railway, for heavy haul railway with heavy axial load, high train density and large freight volume, the subgrade needs to bear stronger load and fatigue effect, which put forward higher requirements for the subgrade quality. Now, there is no mature experience at home and abroad for reference on the improvement and filling technology of soft rock filler for heavy haul railway. Therefore, relying on the newly built Menghua heavy haul railway project, to study the basic engineering properties and improvement measures of soft rock filler; and to discuss the key control parameters by carrying out field compaction technology test; in the field, by select typical section for long-term settlement observation, to analysis the settlement deformation law of foundation and embankment; and to explore the appropriateness of completely weathered soft rock as the filer of heavy haul railway embankment below subgrade bed.

\section{The Engineering Properties of Completely Weathered Soft Rock and Improved Soil Filler}

The test soil was taken from the Yueyang to Ji'an of the Menghua railway, Xinyu south station to Anleping, the cross section mileage is DK1806+729.06 DK1806+858, which is completely weathered soft rock.

\subsection{The engineering properties of the completely weathered soft rock filler}

The engineering properties of filler depend not only on the type of parent rock, but also on the weathering degree. By X-ray diffraction analysis of completely weathered soft rock, it was concluded that the mineral composition is made up of quartz $69.5 \%$, ferric white mica $17.3 \%$, ice feldspar $7.9 \%$, kaolinite $2.1 \%$ and chlorite $1.1 \%$, the sample is mainly quartz and ferric white mica, containing a small amount of clay minerals content of kaolinite and chlorite. The results of X-ray fluorescence spectrometric analysis show that the main chemical composition of the completely weathered soft rock filler is $\mathrm{SiO}_{2}, \mathrm{Al}_{2} \mathrm{O}_{3}, \mathrm{~K}_{2} \mathrm{O}$ and $\mathrm{Fe}$, accounting for about $92 \%$ of the total mass.

According to the code for soil test of railway engineering (TB 10102-2010), we got such data by experiment: the natural water content is $20.7 \%$ and the natural density is $1.63 \mathrm{~g} / \mathrm{cm}^{3}$; the particle 
density $\rho_{\mathrm{s}}$ is measured by graduated flask method; the composition of grain diameters was measured by sieving method and densitometer method, in which the grain diameter above $5 \mathrm{~mm}$ was less than 1.0\%, 0.075 5mm (coarse grain) accounted 14.3\%, 0.005 0.075mm (silt) accounted 81.9\%, $0.002 \sim 0.005 \mathrm{~mm}$ (clay) accounted $2.9 \%$, the content of grain diameter below $0.002 \mathrm{~mm}$ (colloidal particle) was almost zero, it can be seen that the completely weathered soft rock filler is mainly silt; the maximum dry density $\rho_{\text {dmax }}$ and the optimum water content $w_{\text {opt }}$ were obtained by $\mathrm{Z} 2$ heavy compaction test; the liquid limit $w_{\mathrm{L}}$ and the plastic limit $w_{\mathrm{P}}$ were measured by the liquid plastic combine tester; the basic physical indexes of soil sample are listed in table 1.

Table 1 Basic physical indexes of soil sample

\begin{tabular}{|c|c|c|c|c|c|c|}
\hline \multirow{2}{*}{ Physical indexes } & \multirow{2}{*}{$\rho_{\mathrm{s}} /\left(\mathrm{g} / \mathrm{cm}^{3}\right)$} & \multirow{2}{*}{$\rho_{\mathrm{dmax}} /\left(\mathrm{g} / \mathrm{cm}^{3}\right)$} & \multirow{2}{*}{$w_{\mathrm{opt}} / \%$} & \multicolumn{2}{|c|}{$w_{L} / \%$} & \multirow{2}{*}{$w_{\mathrm{P}} / \%$} \\
\hline & & & & $17 \mathrm{~mm}$ & $10 \mathrm{~mm}$ & \\
\hline value & 2.72 & 1.61 & 17.5 & 46.5 & 41.4 & 29.2 \\
\hline
\end{tabular}

As shown in table 1 , the $10 \mathrm{~mm}$ liquid limit of completely weathered soft rock filler is $41.4 \%$, more than $40 \%$; and the plastic index $I_{\mathrm{P}}$ is 12.2 , located between 10 and 17 , according to the code for design on subgrade of railway (TB 10001-2005), it is the high liquid limit silty clay, belonging to the $\mathrm{D}$ group filler, which should be reinforced or improved when used for embankment below subgrade bed.

\subsection{Determination of mixing ratio of cement improved soil filler}

During the construction of the embankment, the P.O 42.5 cement is used to improve the completely weathered soft rock filler, when the mixing ratio is $3.0 \%, 3.5 \%$ and $4.0 \%, \rho_{\text {dmax }}$ obtained by Z2 heavy compaction test are $1.61 \mathrm{~g} / \mathrm{cm}^{3}, 1.62 \mathrm{~g} / \mathrm{cm}^{3}$ and $1.63 \mathrm{~g} / \mathrm{cm}^{3}$ respectively, the corresponding are $16.9 \%, 17.1 \%$ and $17.3 \%$. The test shows that, $\rho_{\text {dmax }}$ and $w_{\text {opt }}$ gradually increase with the increase of cement mixing ratio, which is consistent with the research conclusion of [6].

In order to determine the cement content of completely weathered soft rock filler used in the heavy haul railway embankment below subgrade bed, the specimens with different mixing ratio, compaction coefficient and curing age were prepared, and the unconfined compressive strength test was carried out, the number of parallel specimens in each group was 3 , the size of the specimen (diameter $\times$ height) was $50 \mathrm{~mm} \times 50 \mathrm{~mm}$, and the mean value is taken as the unconfined compressive strength $q_{\mathrm{u}}$, the test results are listed in table 2 .

Table 2 Unconfined compressive strength $(\mathrm{kPa})$

\begin{tabular}{|c|c|c|c|c|}
\hline \multirow{2}{*}{ mixing ratio/\% } & \multirow{2}{*}{ K } & \multicolumn{3}{|c|}{ curing age/d } \\
\hline & & 1 & 7 & 28 \\
\hline \multirow{3}{*}{$\begin{array}{c}\text { completely } \\
\text { weathered soft rock }\end{array}$} & 0.90 & \multicolumn{3}{|c|}{ 126.6(non maintenance) } \\
\hline & 0.92 & \multicolumn{3}{|c|}{ 126.9(non maintenance) } \\
\hline & 0.95 & \multicolumn{3}{|c|}{ 159.2(non maintenance) } \\
\hline \multirow{3}{*}{3.0} & 0.90 & 292.9 & 339.1 & 353.6 \\
\hline & 0.92 & 323.4 & 375.6 & 409.5 \\
\hline & 0.95 & 375.4 & 451.8 & 435.3 \\
\hline \multirow{3}{*}{3.5} & 0.90 & 336.7 & 394.3 & 429.7 \\
\hline & 0.92 & 339.5 & 422.4 & 448.8 \\
\hline & 0.95 & 402.2 & 465.4 & 483.1 \\
\hline \multirow{3}{*}{4.0} & 0.90 & 402.3 & 437.3 & 458.9 \\
\hline & 0.92 & 369.3 & 446.6 & 502.2 \\
\hline & 0.95 & 429.2 & 505.3 & 504.1 \\
\hline
\end{tabular}


As shown in table 2, the mixing ratio has a significant influence on $q_{\mathrm{u}}$ of the cement improved soil, and the mixing ratio increases by $1.0 \%$, the strength increases by about $20 \%$; along with the compaction coefficient increasing, the shows a linearly increase trend; with the extension of curing age, $q_{\mathrm{u}}$ gradually increases, and the strength of $7 \mathrm{~d}$ has reached $90 \%$ of $28 \mathrm{~d}$, which shows that the strength of cement improved soil has increased rapidly in the early stage, while increases slowly in the latter. Under the same compaction coefficient, when mixing ratio is $3.0 \%, 3.5 \%$ and $4.0 \%$ of the cement improved soil, compare with the completely weathered soft rock filler, the $q_{\mathrm{u}}$ of $7 \mathrm{~d}$ is 2.83 , 3.12 and 3.38 times enhanced respectively, indicating that the cement has a well improvement effect.

When the improved soil filler is used to filling the heavy haul railway embankment below subgrade bed, the control indexes in the code [7] are: compaction coefficient $K \geq 0.92$, $7 \mathrm{~d}$ unconfined compressive strength $q_{\mathrm{u}} \geq 300 \mathrm{kPa}$. According to the test results in table 2, under the 0.92 compaction coefficient, $q_{\mathrm{u}}=375.6 \mathrm{kPa}$ for cement improved soil with mixing ratio of $3.0 \%$, it is greater than the control index $300 \mathrm{kPa}$, which meets the standard design requirements. Considering the losses and safety reserves in site construction, it is recommended to increase the cement content by $0.5 \%$, and take $3.5 \%$ as the optimum mixing ratio of cement improved soil.

During the embankment filling, two samples of cement improved soil filler were selected, the actual cement mixing ratio was $3.7 \%$ and $4.1 \%$ by experiment, and mean value was $3.9 \%$, which was basically the same as the target value $3.5 \%$.

\subsection{The mechanical properties of completely weathered soft rock and cement improved soil filler}

In order to obtain the related mechanical indexes and compaction characteristics of the filler, for the completely weathered soft rock and the cement improved soil with the mixing ratio of $3.5 \%$, the corresponding triaxial compression and consolidation tests were carried out.

The triaxial compression test adopts the stress controlled triaxial apparatus, which is carried out on the consolidation and undrained way, and the samples has two species: the optimum water content and the saturation state, and the saturated sample was prepared by the vacuum pumping saturation method. The size of the specimen (diameter $\times$ height) was $61.8 \mathrm{~mm} \times 125 \mathrm{~mm}$, after the specimen installed, load $\sigma_{1}$ was applied after consolidation $12 \mathrm{~h}$ under confining pressure $\sigma_{3}(100,200,300$, $400 \mathrm{kPa}$ ), and the loading time of each stage was $10 \mathrm{~min}$. At the initial stage of the test, the load increment was $100 \mathrm{kPa}$, by observing the trend of the specimen's axial deformation, the load increment was reduced to $50 \mathrm{kPa}$ before the specimen was destroyed, taking the mean value of the damage load and the preceding load as the peak deviatoric stress $\sigma_{1}-\sigma_{3}$ under the confining pressure condition. The damaged stress circle and the strength envelope under different confining pressures are drawn, and the cohesion force $c$ and internal friction angle $\varphi$ obtained are shown in Table 3 . 
Table 3 Results of triaxial compression test

\begin{tabular}{clccc}
\hline & sample state & $K / \%$ & $c / \mathrm{kPa}$ & $\varphi / \square$ \\
\hline \multirow{3}{*}{$\begin{array}{c}\text { completely } \\
\text { weathered soft } \\
\text { rock }\end{array}$} & the optimum water content state & 0.90 & 52.6 & 32.9 \\
\cline { 2 - 5 } & & 0.92 & 65.0 & 33.6 \\
& \multirow{2}{*}{ the saturation state } & 0.95 & 61.3 & 36.4 \\
\hline \multirow{2}{*}{$\begin{array}{c}\text { cement improved } \\
\text { soil of 7d curing } \\
\text { age }\end{array}$} & the optimum water content state & 0.90 & 32.4 & 33.2 \\
\cline { 2 - 5 } & \multirow{2}{*}{ the saturation state } & 0.92 & 31.1 & 34.3 \\
\hline \multirow{2}{*}{ It is } & 0.92 & 128.9 & 35.1 \\
\hline
\end{tabular}

It is known from table 3, the $c$ and $\varphi$ increase with the increase of $K$; the shear strength index of saturated samples is less than the optimum water content state, because of the lubrication of water, and the attenuation degree of $c$ is greater than that of $\varphi$. After improved by cement, under the same compaction coefficient, the increases 2 3 times, and the increase of $\varphi$ is not obvious; after vacuum pumping saturation, $c$ and $\varphi$ of the cement improved soil decreases, but it is still larger than that of the completely weathered soft rock, with higher strength.

The compaction characteristics of soil is obtained by standard consolidation test, diameter of the sample is $61.8 \mathrm{~mm}$, height is $20 \mathrm{~mm}$, first stage pressure is $12.5 \mathrm{kPa}$, compression rate is 1.0 , the maximum pressure of the test is $3200 \mathrm{kPa}$, loading time of each stage is $24 \mathrm{~h}$, and the standard compressibility $a_{\mathrm{v}(1-2)}$ and compression modulus $E_{\mathrm{s}(1-2)}$ of the soil are obtained, the test results are listed in table 4.

Table 4 Results of standard consolidation test

\begin{tabular}{|c|c|c|c|c|}
\hline & sample state & $K / \%$ & $a_{\mathrm{v}(1-2)} / \mathrm{MPa}^{-1}$ & $E_{\mathrm{s}(1-2)} / \mathrm{MPa}$ \\
\hline \multirow{6}{*}{$\begin{array}{l}\text { completely } \\
\text { weathered soft } \\
\text { rock }\end{array}$} & \multirow{3}{*}{ the optimum water content state } & 0.90 & 0.28 & 6.4 \\
\hline & & 0.92 & 0.24 & 7.2 \\
\hline & & 0.95 & 0.18 & 9.3 \\
\hline & \multirow{3}{*}{ the saturation state } & 0.90 & 0.43 & 4.0 \\
\hline & & 0.92 & 0.40 & 4.2 \\
\hline & & 0.95 & 0.35 & 4.8 \\
\hline \multirow{2}{*}{$\begin{array}{c}\text { cement } \\
\text { improved soil of } \\
\text { 7d curing age }\end{array}$} & the optimum water content state & 0.92 & 0.07 & 26.6 \\
\hline & the saturation state & 0.92 & 0.08 & 21.9 \\
\hline
\end{tabular}

It is known from table 4, the compaction characteristics of soil is closely related to the compaction coefficient, with the increase of $K, a_{\mathrm{v}(1-2)}$ decreases gradually and $E_{\mathrm{s}(1-2)}$ is opposite, indicating that the compressibility of the soil is decreasing. For the completely weathered soft rock with the optimum water content state, when the compaction coefficient increased from 0.90 to 0.95 , the $a_{\mathrm{v}(1-2)}$ reduced from $0.43 \mathrm{MPa}^{-1}$ to $0.18 \mathrm{MPa}^{-1}$, all more than $0.1 \mathrm{MPa}^{-1}$, which belongs to medium compression soil; after vacuum pumping saturation, the $a_{\mathrm{v}(1-2)}$ obviously increased and $E_{\mathrm{s}(1-2)}$ greatly reduced, reflecting the compaction characteristics of the completely weathered soft rock filler is greatly affected by water. After improved by cement, $a_{\mathrm{v}(1-2)}$ of the optimum water content state falls to $0.07 \mathrm{MPa}^{-1}$, after vacuum pumping saturation, it is slightly increased to $0.08 \mathrm{MPa}^{-1}$, all less than $0.1 \mathrm{MPa}^{-1}$, which belongs to the low compression soil; $E_{\mathrm{s}(1-2)}$ increased from $7.2 \mathrm{MPa}$ and $4.2 \mathrm{MPa}$ to 26.6MPa and 21.9MPa respectively, which increased 3.69 and 5.21 times, indicating that the 
compaction properties of the cement improved soil filler were significantly improved, also less affected by water, and have well water stability.

\section{Experimental Study on Field Rolling Process}

\subsection{The scheme of field filling test}

The subgrade part of Menghua heavy haul railway project is built according to the new grade I railway standard in the code [8], the filling quality of embankment below subgrade bed is controlled by compaction coefficient and foundation coefficient $K_{30}$.

The field filling test is according to the method of "three stages, four sections, eight processes", and layered buried, layered rolling. First, the grid is divided on the embankment surface according to the predetermined slackly lay thickness and the loading volume of the dump truck, as shown in figure 1. Then, the cement improved soil is transported to construction site by dump truck, and spread paving according to the principle of one grid per vehicle. Then, using the bulldozer for initial leveling, and the grader is used for precise leveling, as shown in figure 2. After paving and leveling, the LSD220H type vibratory roller is used to rolling in the order of static pressure, weak vibration, strong vibration, the working weight of the roller is 20t, and the exciting force of the weak vibration and strong vibration is $270 \mathrm{kN}$ and $370 \mathrm{kN}$ respectively.

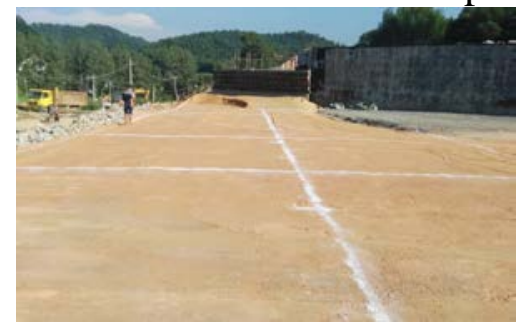

Fig.1 Grid generation

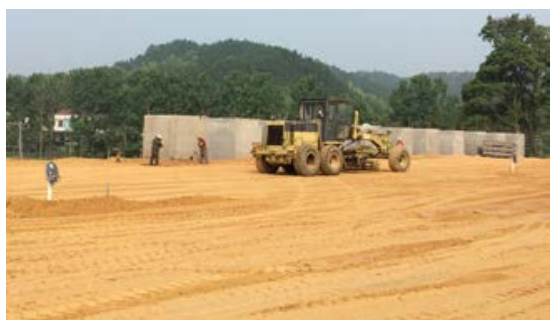

Fig.2 Paving and leveling

During the embankment filling, after each layer paved and levelled, the initial elevation of embankment surface was measured by total station, which is used to calculate slackly lay thickness $h$. Then the compaction technology test is carried out in the order of static pressure 2 times (test) + weak vibration 1 time static pressure 1 time (test) + strong vibration 1 time static pressure 1 time (test), the roller compacted a round-trip for 1 time, and test contents include: the elevation of embankment surface $\Delta H$, the water content $w$ of filler, the compaction coefficient $K$ and the foundation coefficient $K_{30}$, testing process as shown in Figure 3 and Figure 4 . In the test, the compaction coefficient was tested by 6 points per compacted layer, including 2 points on the left and 2 points on the right side, which is $1 \mathrm{~m}$ from the border line of subgrade, 2 points in the middle of the subgrade; the foundation coefficient was tested by 4 points, including 1 point on the left and 1 point on the right side, which is $2 \mathrm{~m}$ from the border line of subgrade, 2 points in the middle of the subgrade; and the average value was taken as the test value.

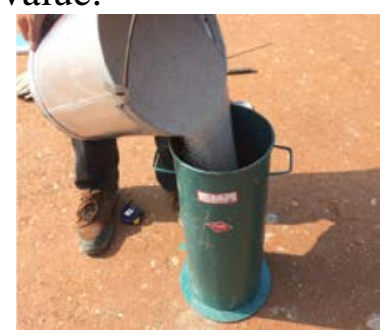

Fig.3 Test of $K$

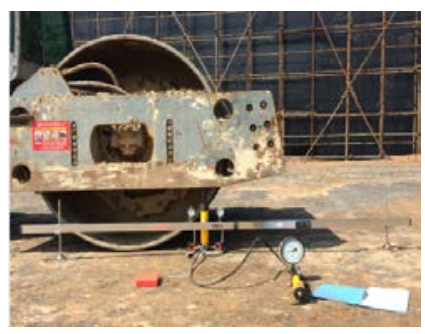

Fig.4 Test of $K_{30}$ 


\subsection{Determination of reasonable slackly lay thickness of cement improved soil filler}

Under the premise that the embankment filling quality meets the design requirements, the reasonable selection of slackly lay thickness $h$ can greatly increase work efficiency and save project investment. Therefore, on the field of cement modified soil filling, the compaction technology test was carried out, the slackly lay thickness are 30,40, 50 and 60cm respectively.

When explore the reasonable value of $h$, in order to avoid the influence of $w$ on the results, according to the range of $w$, the data were divided into three groups: $w_{\text {opt }}-2 \%<w<w_{\text {opt }}$, $w_{\mathrm{opt}}<w<w_{\mathrm{opt}}+2 \%$ and $w>w_{\mathrm{opt}}+2 \%$. The relationship between $K$ and $h$ under different water content conditions is shown in figure 5.

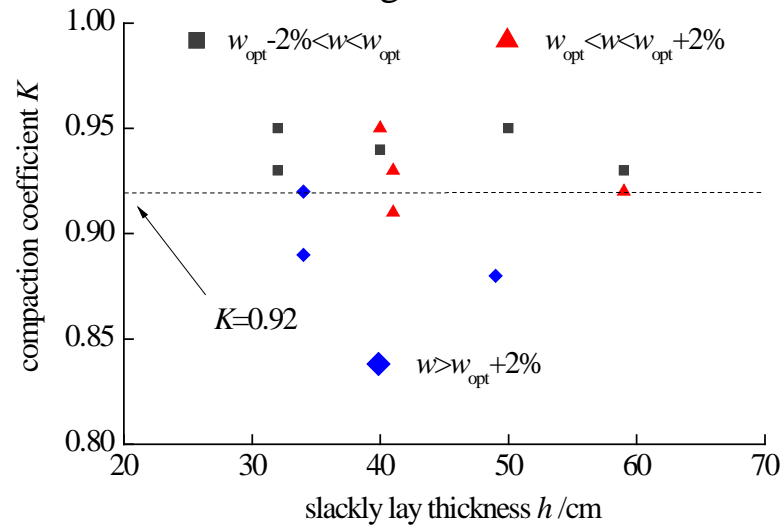

Fig.5 The relationship between $K$ and $h$

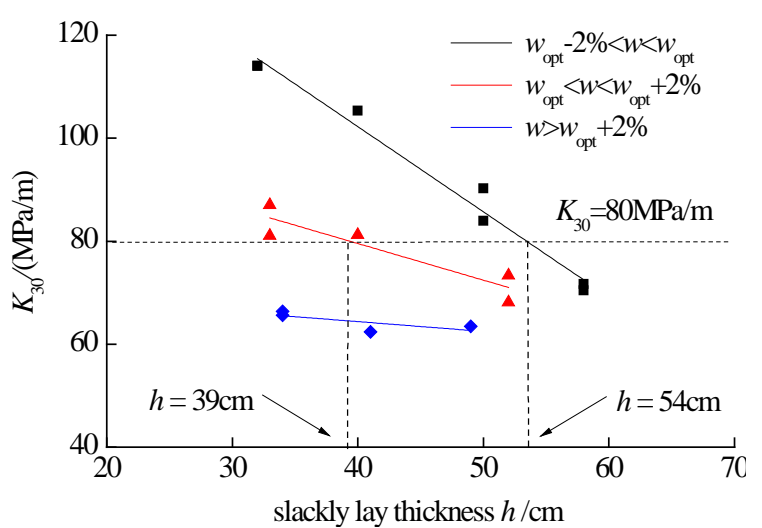

Fig.6 The relationship $K_{30}$ between and $h$

From figure 5, it is known that under the different water content conditions, the $K$ of cement improved soil has no obvious change trend with the increase of $h$. Because the depth of test pit is only $20 \mathrm{~cm}$ when the $K$ of embankment is tested by sand replacement method, the test results can only represent the compaction state of the filler in this depth range, and cannot truly reflect the whole part. When the $h$ is larger, because of the limited influence depth of the vibration roller, in the deep of filler may be not compacted, but in the shallow is generally in a well compacting state, and the high compaction coefficient can be obtained by the sand replacement method.

Through the relation curve between $K$ and $h$ in figure 5, the reasonable value of $h$ cannot be obtained; relationship between $K_{30}$ and $h$ in different water content conditions is shown in figure 6 .

As shown in figure 6 , when the water content of cement improved soil is $w>w_{\text {opt }}+2 \%$, the correlation between $K_{30}$ and $h$ is not significant, and the value of $K_{30}$ is all less than $80 \mathrm{MPa} / \mathrm{m}$ required by code, therefore, the filler water content should be controlled when filling embankments. When the filler $w$ is in the range of $w_{\text {opt }} \pm 2 \%$, the $K_{30}$ shows a linearly decreases trend with the increase of $h$, substituting the control value of $K_{30}$ into the fitting function and obtained: when the water content of filler is located in $w_{\mathrm{opt}}-2 \%<w<w_{\mathrm{opt}}$ and $w_{\mathrm{opt}}<w<w_{\mathrm{opt}}+2 \%$, the corresponding $h$ is $39 \mathrm{~cm}$ and $54 \mathrm{~cm}$, and the loose paving coefficient is 1.08 and 1.05 respectively.

\subsection{The water content control of cement improved soil filler}

When the water content of filler is small, the internal friction resistance and cohesive force between the soil particles are large, which will hinder the dislocation between the particles, and it is not easy to be compacted; with the increase of water content, due to the lubrication of water, under the same compaction work can obtain greater dry density; when the water content is further increased, the volume of water in the soil pores increases continuously, and the pore water cannot be discharged freely in the compaction process, which will affect the compaction effect ${ }^{[9-10]}$. Therefore, there exists 
an optimum water content, so that the best compaction effect can be obtained under the minimum compaction work.

It can be known from the analysis in section 3.2, there is no obvious relationship between $K$ and $h$, therefore, when discussing the relationship between $K$ and $w$, it is not necessary to group according to $h$. According to the field test data, the relationship curve between $K$ and $w$ is shown in figure 7 .

As shown in figure 7, the $K$ increases first and then decreases with the increase of $w$, which is consistent with the laboratory compaction test curve. Using the quadratic polynomial to fit the test data and obtained, when the water content of cement improved soil is $19.1 \%$, the compaction coefficient $K$ reached the peak value 0.94 , which meets the standard design requirement value 0.92 .

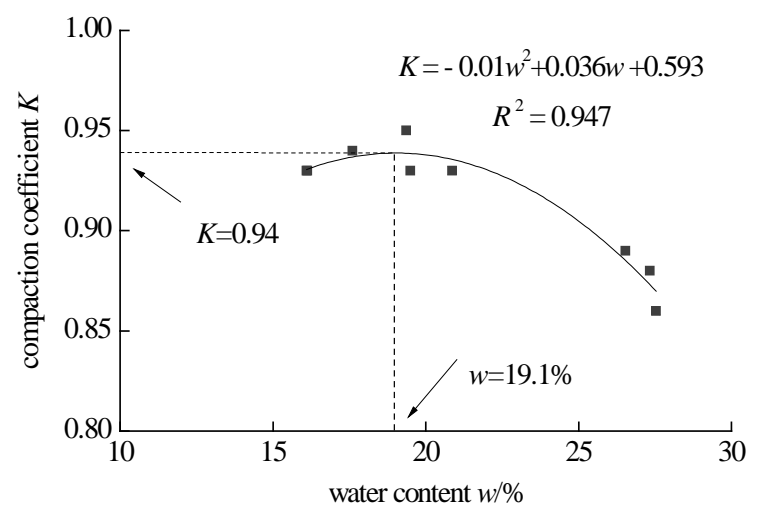

Fig.7 The relationship between $K$ and $h$

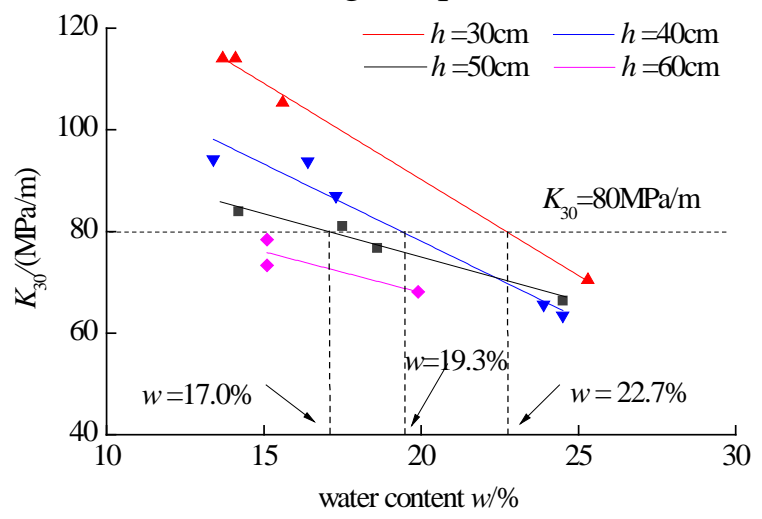

Fig.8 The relationship between $K_{30}$ and $w$

Under the different slackly lay thickness, the relationship between $K_{30}$ and $w$ is shown in figure 8 . From the figure 8 , for the filler of different $h, K_{30}$ gradually decreases with the increase of $w$. When $h=60 \mathrm{~cm}$, the value of $K_{30}$ is less than $80 \mathrm{MPa} / \mathrm{m}$ required by the standard design requirement, during the embankment filling, this thickness should be inappropriate; when the $h$ was 30,40 and $50 \mathrm{~cm}$, substituting the control value of $K_{30}$ into the linearly fitting function, and obtained the corresponding $w$ was $22.7 \%, 19.3 \%$ and $17.0 \%$ respectively; the result shows that the greater the value of slackly lay thickness, the more stringent the control of water content.

Due to the natural water content of completely weathered soft rock is $20.7 \%$, after adding $3.5 \%$ cement, the water content of the improved soil filler is basically equal to $19.1 \%$ of the optimum water content obtained from the field test; when the embankment filling, the compaction coefficient $K$ and foundation coefficient $K_{30}$ can also meet the design requirements at the same time, therefore, it is suggested that the water content of cement improved soil is controlled in the range of $w_{\text {opt }}<w<w_{\text {opt }}+2 \%$.

\subsection{The reasonable rolling compaction combination for cement improved soil filler}

In order to verify the rationality of the rolling compaction combination during the embankment filling, the test data of $h=40 \mathrm{~cm}$ and water content in the range of $w_{\mathrm{opt}}<w<w_{\mathrm{opt}}+2 \%$ are selected, and the relation curve between compaction technology and $K$ with $K_{30}$ is shown in figure 9 . 


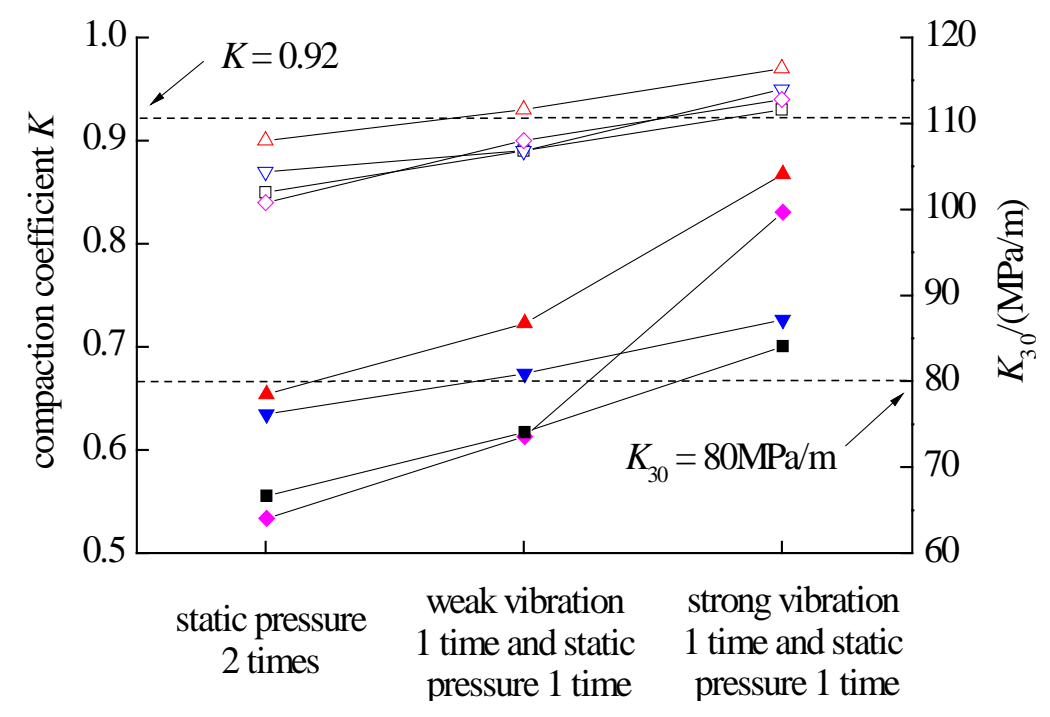

Fig.9 The relationship between compaction technology and $K$ with $K_{30}$

From figure 9, it is known that the $K$ and $K_{30}$ of the cement improved soil filler gradually increase with the rolling process of static pressure + weak vibration static pressure + strong vibration static pressure, finally, the $K$ and $K_{30}$ all reached the standard design requirements: 0.92 and $80 \mathrm{MPa} / \mathrm{m}$, therefore, the rolling order from static to weak and from weak to strong is reasonable.

In summary, when using cement improved soil filler to fill the embankment, it is suggested that $h$ taken for $40 \mathrm{~cm}$, the water content is controlled in the range of $w_{\text {opt }}<w<w_{\text {opt }}+2 \%$, and the rolling compaction combination is carried out with the rolling process of static pressure 2 times + weak vibration 1 time static pressure 1 time + strong vibration 1 time static pressure 1 time.

\section{Conclusion}

For the completely weathered soft rock filler of Yueyang to Ji'an of Menghua heavy haul railway, the systematic laboratory soil test was carried out, the optimum mixing ratio of the cement improved soil was determined, and the detailed compaction technology test was carried out in the field, the settlement of embankment has been observed for a long time by using single-point settlement meter buried in a typical cross section, the following basic conclusions are obtained from the analysis:

(1) The main mineral components of the completely weathered soft rock filler are quartz and iron rich muscovite, and the particles are composed mainly of powder, which is high liquid limit silty clay, belongs to $\mathrm{D}$ group filler, it is not suitable for directly filling the embankment below the subgrade bed, when using the cement to improve, the optimum mixing ratio is $3.5 \%$.

(2) The engineering properties and water stability of cement improved soil are significantly higher than those of the completely weathered soft rock filler. The unconfined compressive strength of 7d is increased by 3.12 times, showing a faster growth in the early stage and slower in the later period; the cohesive force increases by 2 3 times, the increase of internal friction angle is not obvious; the compressibility decreases from $0.24 \mathrm{MPa}^{-1}$ to $0.07 \mathrm{MPa}^{-1}$, the soil changes from medium compressibility to low compressibility, and the compression modulus is increased by 3.69 times.

(3) The compaction coefficient $K$ of the cement improved soil filler is not closely related to the slackly lay thickness, and the foundation coefficient $K_{30}$ gradually decreases with the increase of the slackly lay thickness; with the increase of water content, the $K$ increases first and then decreases, and the $K_{30}$ gradually decreases. When the slackly lay thickness is $40 \mathrm{~cm}$, and the water content is controlled in the range of $w_{\text {opt }}<w<w_{\text {opt }}+2 \%$, with the rolling compaction combination of static pressure 2 times + weak vibration 1 time static pressure 1 time + strong vibration 1 time static 
pressure 1 time, the detection index of embankment can meet the standard design requirements.

\section{References}

[1] BO Gonglin, KOJIMA Kobayashi. Design and construction of large scale subgrade filling with soft rock and waste slag [J].Translated by China Academy of Railway Sciences. Soils and Foundations, 1984, 32(7):53-59.

[2] Mingxin Zheng, tao Fang, Xinhong Diao, et al. Experimental study on feasibility of filled subgrade with weathered soft rock [J]. Rock and Soil Mechanics, 2005, 26(s):53-56.

[3] Wei Yuan. Applicability analysis and settlement study of soft rock fill in high speed railway [D]. Changsha: Central South University, 2009.

[4] M Adom-Asamoah, RO Afrifa. A study of concrete properties using phyllite as coarse aggregates [J]. Materials and Design, 2010, 31(9): 4561-4566.

[5] Qixiang Qing, Yonghe Wang, Guangyao Li, et al. Indoor experimental study on express railway embankment with weathered soft rock [J]. Rock and Soil Mechanics, 2006, 27(7):1119-1124.

[6] Ping Hu, Yonghe Wang, Qixiang Qing. Study on Indoor Tests of the Characteristics of Modified Weathered Soft Rock [J]. Journal of Hunan University of Technology, 2007, 21(2):96-99.

[7] National Railway Administration of the People's Republic of China. TB 10625-2017 Code for Design of Heavy Haul Railway[S]. Beijing: China Railway Publishing House, 2017.

[8] Ministry of Railways of the People's Republic of China. TB 10001-2005 Code for design on subgrade of railway[S]. Beijing: China Railway Publishing House, 2005.

[9] Qingguo Guo. Engineering characteristics and application of coarse-grained soil [M]. Zhengzhou: The yellow river water conservancy press, 1998:55-61.

[10] Bing Li, Shengjie Jiao. Vibratory roller and vibratory compaction [M]. Beijing: China communications press, 2001: 246-264. 